\title{
Analgesic efficacy of intravenous paracetamol versus intravenous tramadol after caesarean section: a single blind randomized controlled study
}

\author{
Kumari Usha Rani, Vijay Zutshi, Madhumita Patel*, Sheeba Marwah
}

\begin{abstract}
Department of Obstetrics and Gynaecology, Vardhman Mahavir Medical College and Safdarjung Hospital, New Delhi, India
\end{abstract}

Received: 20 September 2016

Accepted: 18 October 2016

*Correspondence:

Dr. Madhumita Patel,

E-mail: mickey_patel80@yahoo.com

Copyright: ( ) the author(s), publisher and licensee Medip Academy. This is an open-access article distributed under the terms of the Creative Commons Attribution Non-Commercial License, which permits unrestricted non-commercial use, distribution, and reproduction in any medium, provided the original work is properly cited.

\section{ABSTRACT}

Background: Caesarean section is one of the commonest surgeries performed in obstetrics. Adequate management of postoperative pain leads to early mobilization and proper newborn care. The purpose of this study was to compare the analgesic efficacy and side effect profile of Paracetamol versus Tramadol in women undergoing caesarian section.

Methods: A single-blind randomized controlled interventional study was conducted in Department of Obstetrics and Gynecology, Vardhman Mahavir Medical College and Safdarjang Hospital, New Delhi over a period of six months from May 2015 to Oct 2015. 100 women undergoing caesarean section under spinal anaesthesia were divided in two groups (50 in each group) using computer generated randomization. One group received Intravenous Paracetamol $1000 \mathrm{mg}$ and another group Intravenous Tramadol $50 \mathrm{mg}$. The drugs were given 8 hourly for 24 hours. The primary outcome measures were the degree of pain relief during the entire observation period by doing visual analogue scale (VAS) scoring and need of rescue analgesia if any (administered if the VAS score $>6$ ); secondary outcome measures were side effects on mother and baby.

Results: The pain scores were low in both groups across various time interval except at 6 hours in Paracetamol group $(\mathrm{p}=0.673)$ and at 8 hours in Tramadol group $(\mathrm{p}=0.194)$. Requirement for rescue analgesia was comparable in both the groups $(16 \%$ vs. $10 \%, \mathrm{p}=0.372)$. However maternal side effects were more in Tramadol group $(8 \%$ vs. $34 \%, \mathrm{p}=$ $0.001)$.

Conclusions: Both Paracetamol and Tramadol achieve satisfactory pain control after caesarean section but Tramadol causes significant side effects in mother compared to paracetamol.

Keywords: Analgesia, Caesarean section, Paracetamol, Tramadol

\section{INTRODUCTION}

Adequate pain control after cesarean section is required for early mobilization of mother and to take care of her newborn as early as possible. Proper analgesia is important in short term following any surgical intervention. ${ }^{1}$ Taking into account the importance of maternal care in the first few hours after delivery and necessity of relaxation for her to communicate with the infant and to start breast feeding, pain relief after caesarean section is of high importance. ${ }^{2,3}$ Besides adequate post operative analgesia not only increase patient satisfaction but may also diminish the duration of hospital stay and reduce the risk of complications. ${ }^{4}$

Therefore multimodal and preventive approach to provide postoperative analgesia is gaining popularity these days. For this reason Paracetamol is now being explored for same. It is a nonopioid analgesic ${ }^{5}$ and thought to exert its analgesic activity by inhibiting the synthesis of prostaglandins in central nervous system. It rapidly passes through blood-brain barrier, reaches a high concentration in the cerebrospinal fluid and has an antinociceptive effect mediated by the central nervous 
system. ${ }^{6,7}$ Injectable paracetamol provides pain relief within 5-10 minutes following administration. The peak analgesic effect is achieved in 1 hour and the duration of this effect lasts 4-6 hour. ${ }^{8}$ It is devoid of any major adverse effects like respiratory and circulatory depression and has no sedative effect.

From times in memorial opioids have been used for pain relief, amongst which Tramadol is common. Tramadol acts via selective interaction with mu receptors, which are responsible for nociception and has weak pharmacodynamic activity on other opioid receptors. At the same time it acts synergistically on neuroamine transmission by inhibiting synaptic noradrenaline reuptake and inducing intrasynaptic serotonin (5hydroxytryptamine) release. ${ }^{9}$ However the use of opioid may sometimes be limited because of concern regarding their side effects especially respiratory depression.

Keeping all this in mind, the present study was proposed with the aim of comparing the analgesic efficacy of Paracetamol with Tramadol as postoperative pain relief in caesarean section and to compare side effect profile of both the drugs in order to justify the replacement of opioid analgesics with Paracetamol in parturient women.

\section{METHODS}

The proposed study was conducted in Department of Obstetrics and Gynecology, Vardhman Mahavir Medical College and Safdarjung Hospital New Delhi over a period of six months from May 2015 to Oct 2015. The study was approved by institute ethical committee. 100 parturient who were undergoing cesarean delivery under spinal anaesthesia were enrolled into the study. Patients were divided into two equal groups using computer generated randomization with 50 women in each group.

Patients with known contraindication/Allergic to paracetamol or Tramadol, pregnancy with medical disorders (hepatic, renal, diabetes, cardiovascular and pulmonary disease) preeclampsia/eclampsia cases, chorioamnionitis, women taking monoamine oxidase inhibitors and those who received any analgesics till four hours before surgery were excluded from the study.

Group A received intravenous paracetamol $1000 \mathrm{mg}$ in $100 \mathrm{ml}$ of normal saline over 15 minutes and Group B received intravenous Tramadol 50mg over 2-3 minutes and the drugs were repeated eight hourly for three doses. The drug was started postoperatively at first sensation of pain perceived by the patient. It was a single blinded study and only patient was blind about the analgesic drug administered.

Primary outcome measured were degree of pain relief as determined by drop in Visual Analogue Scale and need of rescue analgesia if any. Adverse effect on mother and neonate were evaluated for 24 hours postoperatively as secondary outcome and recorded on predesigned study proformas.

Degree of pain relief was measured on visual analogue scale (VAS) of 0 to $10(0=$ no pain to $10=$ worst pain). Pain was assessed just before giving medicine and after $1 / 2$ hour, 1 hour, 2 hour, 4 hour, 6 hour, 8 hour and 24 hour after analgesic administration. Additional analgesia (rescue analgesia) before 8 hours if required (VAS score more than or equal to 6 ) was managed by giving injection pethidine $50 \mathrm{mg}$ intramuscularly.

\section{Statistical analysis}

Data was deciphered at end of study and appropriate statistical test were applied as required. Comparison between the two groups characteristics were made either by using Fisher exact test if data was categorically variable or by Mann-Whitney test if data was continuous and characteristics were expressed as medians and ranges. All outcome measures were compared between the two groups by using the $\mathrm{X}^{2}$ test or Fisher exact test, where appropriate. All statistical analyses were performed by using a statistical Software program (SPSS version 22, IBM Corp Armonk, NY/USA). P $\leq 0.05$ was considered statistically significant.

\section{RESULTS}

The mean age of women in Paracetamol group was 26.6 \pm 4.79 years and of Tramadol group was 25.4 \pm 5.20 years $(p>.05)$. There was no statistically significant difference in other variables also like parity, indication of caesarean section, duration of surgery and whether it was a repeat or primary caesarean section.

Table 1: Maternal characteristics and obstetric data.

\begin{tabular}{|llll|}
\hline Variables & $\begin{array}{l}\text { Paracetamol } \\
\mathrm{n}=50\end{array}$ & $\begin{array}{l}\text { Tramadol } \\
\mathrm{n}=50\end{array}$ & $\begin{array}{l}\mathrm{p} \text { - } \\
\text { Value }\end{array}$ \\
\hline $\begin{array}{l}\text { Age (years) } \\
\text { (mean } \pm \text { SD) }\end{array}$ & $26.6 \pm 4.79$ & $25.4 \pm 5.20$ & $>0.05$ \\
\hline Nulliparity & 23 & 22 & $>0.05$ \\
\hline Multiparity & 27 & 28 & $>0.05$ \\
\hline $\begin{array}{l}\text { Elective } \\
\text { caesarean }\end{array}$ & 11 & 7 & $>0.05$ \\
\hline $\begin{array}{l}\text { Emergency } \\
\text { caesarean }\end{array}$ & 39 & 43 & $>0.05$ \\
\hline $\begin{array}{l}\text { Duration of } \\
\text { surgery in } \\
\text { hours (mean) }\end{array}$ & 44.75 & 45.58 & $>0.05$ \\
\hline $\begin{array}{l}\text { Primary } \\
\text { caesarean }\end{array}$ & 37 & 35 & $>0.05$ \\
\hline $\begin{array}{l}\text { Repeat } \\
\text { caesarean }\end{array}$ & 13 & 15 & $>0.05$ \\
\hline
\end{tabular}

It was observed that there was significant pain relief in both the groups at various time intervals except at 6 hours in Paracetamol group $(\mathrm{p}=0.637)$ and at 8 hours in 
Tramadol group $(\mathrm{p}=0.194)$. In Paracetamol group mean VAS change was lowest at 6 hours and in tramadol group at 8 hours, suggestive of least pain control at this point of time. This suggests that effect of Paracetamol starts weaning off by 6 hour after initial dose and of Tramadol by 8 hour.

Table 2: Pain assessment by VAS scoring.

\begin{tabular}{|lllll|}
\hline Pain & \multicolumn{2}{l|}{ Paracetamol } & \multicolumn{2}{l|}{ Tramadol } \\
assessment, & $\begin{array}{l}\text { Mean } \\
\text { VAS } \\
\text { VAS score }\end{array}$ & $\begin{array}{l}\text { P- } \\
\text { change }\end{array}$ & $\begin{array}{l}\text { Mean } \\
\text { VAS } \\
\text { change }\end{array}$ & $\begin{array}{l}\text { P- } \\
\text { value }\end{array}$ \\
\hline $\begin{array}{l}\text { VAS after 30 } \\
\text { min }\end{array}$ & 0.260 & 0.018 & 0.460 & 0.009 \\
\hline VAS after 1 hr & 0.420 & 0.003 & 0.820 & 0.000 \\
\hline VAS after 2 hr & 0.580 & 0.000 & 0.920 & 0.000 \\
\hline VAS after 4 hr & 0.560 & 0.000 & 0.840 & 0.000 \\
\hline VAS after 6 hr & -0.080 & 0.637 & 0.480 & 0.004 \\
\hline VAS after 8 hr & 0.460 & 0.019 & 0.260 & 0.194 \\
\hline VAS after 12 hr & 0.640 & 0.000 & 0.660 & 0.000 \\
\hline VAS after 24 hr & 1.200 & 0.000 & 1.020 & 0.000 \\
\hline
\end{tabular}

When contrasting VAS scoring of both groups with time on a linear graph, pain control was comparable in both the groups.

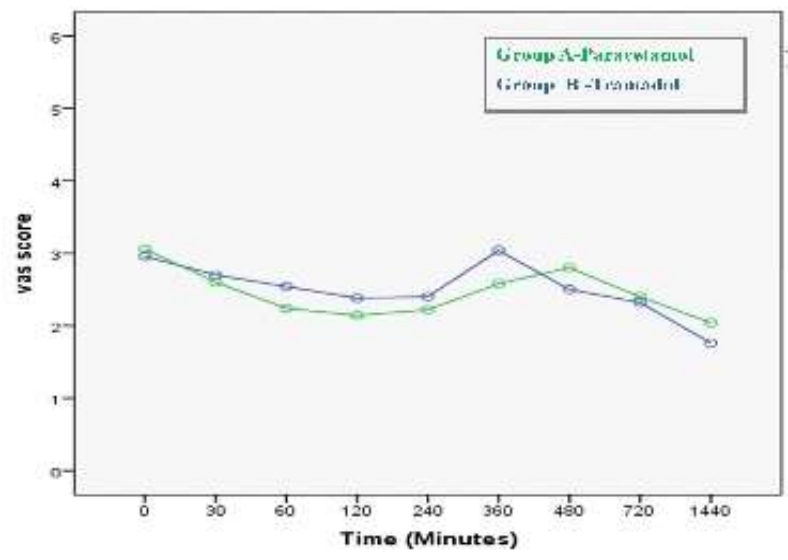

Figure 1: Linear graph showing comparable analgesic effect in Paracetamol and Tramadol group.

Eight out of fifty patients in Paracetamol group and five out of fifty patients in Tramadol group required rescue analgesia for pain relief; however the difference was not statistically significant.

Seventeen out of fifty patients(34\%) in Tramadol group had various side effects like nausea, vomiting, dizziness, headache dryness of mouth and breathing difficulty whereas four out of fifty patients $(8 \%)$ in Paracetamol group (two patients had nausea, one had dizziness and one had vomiting) had side effects. This difference was statistically significant. There was no neonatal side effect in Tramadol while one neonate in Paracetamol group had sleeplessness which was not statistically significant.

Table 3: Rescue drug and side effects.

\begin{tabular}{|lllll|}
\hline & $\begin{array}{l}\text { Paracetamol } \\
\text { N=50 }\end{array}$ & $\begin{array}{l}\text { Tramadol } \\
\text { N=50 }\end{array}$ & $\begin{array}{l}\text { Chi } \\
\text { square }\end{array}$ & $\begin{array}{l}\mathrm{p} \\
\text { value }\end{array}$ \\
\hline $\begin{array}{l}\text { Rescue } \\
\text { drug } \\
\text { required }\end{array}$ & $8(16 \%)$ & $5(10 \%)$ & 0.796 & 0.372 \\
\hline $\begin{array}{l}\text { Side } \\
\text { effect on } \\
\text { mother }\end{array}$ & $4(8 \%)$ & $17(34 \%)$ & 10.187 & 0.001 \\
\hline $\begin{array}{l}\text { Side } \\
\text { effect on } \\
\text { baby }\end{array}$ & $1(2 \%)$ & $0(0 \%)$ & $1.000 *$ & \\
\hline
\end{tabular}

* Fischer's test

\section{DISCUSSION}

Caesarean section constitutes a public health priority because it is one of the most common surgeries in the obstetrics with its rates being increased due to increasing marital age, legal issues and socio-economic status of the community. ${ }^{10,11}$ Thus prevention of postoperative complications of caesarean section is of great importance. $^{12}$ One of the most common postoperative complications of caesarean is pain after surgery. ${ }^{13}$ Several methods including drugs are available for this purpose, each with different efficacy. ${ }^{14,15}$

In the current study we evaluated the deployment of IV paracetamol as a suitable alternative to IV tramadol for postoperative pain relief in caesarean section and we found that pain relief was adequate in both the groups. However more maternal side effects were found in Tramadol group.

The results of our study are consistent with following studies:

Cochrane review done by Laurence Toms1 titled 'Single dose paracetamol (acetaminophen) with and without codeine for postoperative pain' and concluded that a single dose of paracetamol provides effective analgesia for about half of patients with acute postoperative pain, for a period of about four hours and is associated with few, mainly mild adverse events. ${ }^{16}$

M Inal observed that in meperidine group most of the patients had VAS score higher than seven in the second hour after the caesarean section and received extra analgesics but in the paracetamol group most of the patients had lower VAS scores in the second hour after the operation and had the first extra analgesic six hours after the operation. ${ }^{17}$ Side effects were all similar while in our study side effects were more in tramadol group.

Heidar Darvish concluded that Paracetamol and Diclofenac combination would have a better efficacy in 
postoperative pain control and need reduction to additive analgesia compared to Meperidine. The frequency of drug adverse effects was the same between the two groups $(\mathrm{P}>0.05){ }^{18}$

Uysal HY et al concluded that IV formulation of paracetamol was associated with similar analgesic properties and early recovery to that of IV tramadol after adenotonsillectomy in children. ${ }^{19}$

Mustafaeva and Mizikov found that despite the high efficacy of tramadol, the quality of analgesia using IV paracetamol was almost five times better with fewer adverse effects. $^{20}$

Aken et al found that there was no difference in pain relief between morphine and paracetamol when given after dental surgery and adverse effects were significantly larger in the morphine group. ${ }^{21}$

Muhammad Asghar Ali did a comparative study between intravenous paracetamol and fentanyl for intraoperative and postoperative pain relief in dilatation and evacuation and demonstrated the usefulness of IV paracetamol which may be as effective as fentanyl in dilation and curettage procedures. $^{22}$

Following few studies showed different results for pain control when compared to our study but side effect profile of almost all the studies were similar to our study.

Mitra $S$ et all concluded that diclofenac-tramadol combination was overall more efficacious than diclophenac-acetaminophen combination for pain relief after caesarean section but associated with higher incidence of post-operative nausea. ${ }^{23}$

Munishankar B concluded that Patients given a combination of diclofenac and paracetamol used 38\% less morphine compared to patients given paracetamol after caesarean section while in our study pain relief was adequate with paracetamol alone indicating no additional benefit of combination therapy. ${ }^{24}$

S Aghamir et al showed that Propacetamol could be considered as a safe alternative post-operatively for pain management after urologic surgery when compared to Tramadol, however its use for severe pain management leads to inefficient pain control, necessitating supplementary analgesics. ${ }^{25}$ While our study showed that paracetamol is equally effective for postoperative pain and need of additional analgesic is comparable in both groups.

Rawal et al compared oral metamizol, oral tramadol and iv paracetamol for the postoperative analgesia at home after ambulatory hand surgery and showed that tramadol provided the most effective analgesia as compared with the other group but side effects were higher in tramadol group. ${ }^{26}$

\section{Limitation of this study}

The sample size of this study was small; hence it might be difficult to generalize the results, larger and multicentric trials are required for the same.

\section{CONCLUSION}

Paracetamol is better than Tramadol for postoperative pain relief in caesarean patients owing to its comparable analgesic efficacy with lesser maternal side effects. Hence mother may be able to start breast feeding at the earliest and can take care of her newborn properly.

Funding: No funding sources

Conflict of interest: None declared

Ethical approval: The study was approved by the Institutional Ethics Committee

\section{REFERENCES}

1. Verstraete S, Van de Velde M. Post-cesarean section analgesia. Acta Anaesthesiologica Belgica 2012;63(4):147-67.

2. Lim NL, Lo WK, Chong JL, Pan AX. Single dose diclofenac suppository reduces post-Cesarean PCEA requirements. Canaddian Journal of Anaesthesiology 2001;48(4):383-86.

3. Pakar Tadbiri SH, Rahimi E. Comparison of morphine and piroxicam in decreasing post cesarean pain. Scientif J Kurdistan Uni Med Sci. 2001;19:10-4.

4. Pan PH, Coghill R, Houle TT, Seid MH, Lindel WM, Parker RL. Multifactorial preoperative predictors for post-caesarean section pain and analgesic requirement. Anesthesiology. 2006;104:417-25.

5. Bjune K, Stubhaug A, Dodgson MS, Breivik H. Additive analgesic effect of codeine and paracetamol can be detected in strong, but not moderate, pain after Caesarean section. Baseline pain-intensity is a determinant of assay-sensitivity in a postoperative analgesic trial. Acta Anaesthesiology Scandinavica. 1996;40:399-407.

6. Bannwarth B, Netter P, Lapicque F, Gillet P, Péré P, Boccard E, et al. Plasma and cerebrospinal fluid concentrations of paracetamol after a single intravenous dose of propacetamol. British Journal of Clinical Pharmacology. 1992;34:79-81.

7. Piletta P, Porchet HC, Dayer P. Central analgesic effect of acetaminophen but not of aspirin. Clinical Pharmacology and Therapeutics. 1991;49:350-54.

8. Arici S, Gurbet A, Türker G, Yavascaoglu B, Sahin S. Preemptive analgesic effects of intravenous paracetamol in total abdominal hysterectomy. Agri. 2009;21:54-61.

9. Bono AV, Cuffari S. Effectiveness and tolerance of tramadol in cancer pain: A comparative study with respect to buprenorphine. Drugs. 1997;53(2):40-9. 
10. Labib NY, Mortada MM, Guirguis WW, Abd ElAziz HM. Cesarean section deliveries in one health insurance hospital in Alexandria. Journal Egypt Public Health Association. 2007;82(3-4):299-317.

11. Shoar S, Esmaeili S, Safari S. Pain Management after Surgery: A Brief Review. Anesthesiology and Pain Medicine. 2012;1(3):184-6.

12. Tampakoudis P, Assimakopoulos E, Grimbizis G, Zafrakas M, Tampakoudis G, Mantalenakis S, et al. Cesarean section rates and indications in Greece: data from a 24-year period in a teaching hospital. Clinical and Experimental Obstetrics and Gynecology. 2004;31(4):289-92.

13. Imani F. Postoperative pain management. Anesthesiology and Pain Medicine. 2011;1(1):6-7.

14. Moradi M, Esmaeili S, Shoar S, Safari S. Use of Oxycodone in Pain Management. Anesthesiology and Pain Medicine. 2012;1(4):262-64.

15. Sinha A, Paech M, Ledger R, McDonnell N, Nathan E. A Clinical Evaluation of the Gemstar and the Ambit Pump for Patient- Controlled Epidural Analgesia. Anesthesiology and Pain Medicine. 2012;2(2):66-71.

16. Toms L, McQuay, Derry S, Moore RA. Pain Research and Nuffield Department of Anaesthetics, University of Oxford, Oxford, UK Cochrane Database Syst Rev. 2008;(4):CD004602.

17. Inal MT, Cel N, Tuncay FIV. Paracetamol Infusion Is Better Than I.V. Meperidine Infusion for Postoperative Analgesia after Caesarean Section. The Internet Journal of Anesthesiology. 2006;15(1):45-8.

18. Heidar D, Behrouz MA, Shali SMK, Ali Tajik. Analgesic Efficacy of Diclofenac and Paracetamol vs. Meperidine in Cesarean Section. Anesthesiology and Pain Medicine. 2014;4(1):e9997.

19. Uysal HY, Takmaz SA, Yaman F, Baltaci B, Basar $\mathrm{H}$. The efficacy of intravenous paracetamol versus tramadol for postoperative analgesia after adenotonsillectomy in children. Journal of Clinical Anesthesia. 2011;23(1):53-7.

20. Mustafaeva MN, Mizikov VM. Paracetamol (Perfalgane) as analgesic component of medical sedation. Anesteziologiia I Reanimatologiia. 2011;2:23-6.

21. Aken HV, Thys L, Veekman L. Assessing analgesia in single and repeated administrations of proparacetamol for postoperative pain: comparison with morphine after dental surgery. Anesthesia and Analgesia. 2004;98:159-65.

22. Ali MA, Shamim F, Chughtai S. Comparison between intravenous paracetamol and fentanyl for intraoperative and postoperative pain relief in dilatation and evacuation. Journal of Anaesthesiology Clinical Pharmacology. 2015;31:54-8.

23. Mitra S, Khandelwal P, Sehgal A. Diclofenactramadol vs diclofenac-acetaminophen combinations for pain relief after caesarean section. Acta Anaesthesiology Scandinavica. 2012;56(6):706-11.

24. Munushenkar B, Fettes P, Moore C, Mcleod GA. A double-blind randomized controlled trial of paracetamol, diclofenac or the combination for pain relief after cesarean section. International Journal of Obstetric Anesthesia. 2008;17:9-14.

25. Aghamir SK, Mojtahedzadeh M, Alizadeh F, Alizadeh F, Khalili H, Najafi A, et al. Paracetamol Vs. tramadol for post-operative pain management after urologic surgery. The Internet $\mathrm{J}$ of Pharmacology. 2005;4:2

26. Rawal N, Macquaire V, Catalá E, Berti M, Costa R, Wietlisbach M. Tramadol/paracetamol combination tablet for postoperative pain following ambulatory hand surgery: a double-blind, double-dummy, randomized, parallel-group trial. J of Pain Research. 2011;4:103-10.

Cite this article as: Kumari UR, Zutshi V, Patel M, Marwah S. Analgesic efficacy of intravenous paracetamol versus intravenous tramadol after caesarean section: a single blind randomized controlled study. Int J Reprod Contracept Obstet Gynecol 2016;5:4285-9. 